OPEN ACCESS

Edited by:

Monica Trif,

Centre for Innovative Process

Engineering, Germany

Reviewed by:

Aswir Abd Rashed,

National Institutes of Health $(\mathrm{NIH})$,

Malaysia

Sonia Socaci,

University of Agricultural Sciences and Veterinary Medicine of

Cluj-Napoca, Romania

*Correspondence:

Nasrin Omidvar omidvar.nasrin@gmail.com

Specialty section

This article was submitted to Nutrition and Sustainable Diets,

a section of the journal

Frontiers in Nutrition

Received: 05 October 2021 Accepted: 24 November 2021 Published: 22 December 2021

Citation:

Sobhani SR, Omidvar N, Abdollahi Z and Al Jawaldeh A (2021) Shifting to a

Sustainable Dietary Pattern in Iranian

Population: Current Evidence and

Future Directions.

Front. Nutr. 8:789692.

doi: 10.3389/fnut.2021.789692

\section{Shifting to a Sustainable Dietary Pattern in Iranian Population: Current Evidence and Future Directions}

\author{
Seyyed Reza Sobhani ${ }^{1}$, Nasrin Omidvar ${ }^{2 *}$, Zahra Abdollahi ${ }^{3}$ and Ayoub Al Jawaldeh ${ }^{4}$ \\ ${ }^{1}$ Department of Nutrition, Faculty of Medicine, Mashhad University of Medical Sciences, Mashhad, Iran, ${ }^{2}$ Department of \\ Community Nutrition, National Nutrition and Food Technology Research Institute (WHO Collaborating Center), Faculty of \\ Nutrition Sciences and Food Technology, Shahid Beheshti University of Medical Sciences, Tehran, Iran, ${ }^{3}$ Department of \\ Nutrition, Ministry of Health and Medical Education, Tehran, Iran, ${ }^{4}$ World Health Organization Regional Office for the Eastern \\ Mediterranean, World Health Organization, Cairo, Egypt
}

The need for a shift in diet toward a more sustainable one has reached an urgency in certain regions, including Iran, due to more rapid climate change and a higher level of vulnerability. This study was undertaken to identify and summarize available data on changes required in the current Iranian diet to make it more sustainable and the extent to which current policies in the country have addressed such a shift. In this study, PubMed, Scopus, and Web of science, as well as Iranian scientific search engines, including Scientific Information Database and Magiran, were systematically searched from January 1990 to July 2021. A total of 11 studies and policy analyses were included in this study. Based on the findings, moving Iranian diet toward sustainability will require increase in consumption of dairy, fruits, vegetables, cereals, poultry, and legumes and decrease in consumption of bread, rice, pasta, red meat, eggs, fats, sugars, and sweets. There has been a great deal of effort and investment on policies and strategies to decrease the amount of sugar, salt, and fat (specifically trans-fatty acids) in the Iranian diet, which makes it more sustainable healthwise. Several policies and programs have been implemented to tackle non-communicable diseases (NCDs) by reducing access to unhealthy foods, which is in line with health dimension of a sustainable diet. However, there is almost no direct address to ecological aspect of sustainable diet in the food and nutrition policy documents in the ccountry. Development of an enabling environment to a sustainable diet will require policy and actions to improve public awareness, support study to provide evidence and identify possible alternatives, and plan and implement interventions/programs to promote and facilitate healthy and sustainable diets.

Keywords: sustainable diet, dietary change, environmental footprint, nutrition, Iran

\section{INTRODUCTION}

Over the last decades, nations have experienced urbanization and consequently transformational adaptation of food systems that have resulted in substantial change in their traditional diet known as nutrition transition (1). These dietary changes have been accompanied by a higher intake of calorie and resource-intensive foods, e.g., animal products (meats and dairy), vegetable oil, and sugar (2). Based on the changes 
that have been happening, it is foreseen that there is $70 \%$ gap, called "food gap," between the crop calories available in 2006 and expected calorie demand in 2050 (3). One of the options for closing this gap by 2050, as stated in the sustainable development goals (SDGs), is through shifts in food demand including shifting diets, reducing food waste, and avoiding competition from bioenergy (4). Such a shift has the potential to impact health of people and environment.

There is a growing literature on health co-benefits of sustainable diets at global, regional, national, and subnational (modeling) studies estimating the potential impact of dietary change on both the environment and health (4). According to the Food and Agriculture Organization (FAO) definition, "sustainable diets are those diets with low environmental impacts, which contribute to food and nutrition security and healthy life for present and future generations. Sustainable diets are protective and respectful of biodiversity and ecosystems, culturally acceptable, accessible, economically fair and affordable, nutritionally adequate, safe, and healthy, while optimizing natural and human resources" (5). Recent studies have shown that diets comprising reduced animal sources (specifically reduced red and processed meat) and high levels of plant-based foods including fruits and vegetables are not only associated with decrease in non-communicable diseases (NCDs) $(6,7)$, but can result in lower environmental footprints $(8,9)$.

The need for a shift toward a more sustainable diet may have more urgency in certain regions. An example is Iran, a middleincome country located in the Middle East that is mostly an arid and semi-arid region where climate change is occurring more rapidly. It is expected that the amount of precipitation in this region drop by $20 \%$ within the next century, which makes the region more vulnerable (10). In addition, over the last four decades, due to industrialization and rapid urbanization, nutrition transition and major changes in the food system in the country have occurred that put further pressure on the environment as well as health of the population (11). Therefore, considering the urgency of the problem and the fact that there is not one sustainable diet, there is a need to define the most sustainable choices based on food availability and dietary pattern in each region (12).

There are relatively limited data available on sustainability aspects of the Iranian diet. This study was undertaken to identify and summarize available data on changes required in the current Iranian diet to make it more sustainable and the extent to which current policies in the country has addressed such a shift.

\section{METHODS}

\section{Conceptual Framework}

Sustainable diets are diets that consider how the food system influences health, environmental outcomes, and vice versa (5). Therefore, sustainable healthy diets are dietary patterns that promote all the dimensions of health and well-being of an individual; in the meantime, sustainable healthy diets have low environmental pressure and impact and are accessible, affordable, safe, equitable, and culturally acceptable (5). Sustainable healthy diets aim to achieve optimal growth and development of all the individuals and support functioning and physical, mental, and social well-being at all the life stages for present and future generations; contribute to preventing all the forms of malnutrition (i.e., undernutrition, micronutrient deficiency, overweight, and obesity); reduce the risk of diet-related NCDs and support the preservation of biodiversity and planetary health (12). In other words, sustainable healthy diets must combine different dimensions of sustainability to avoid unintended consequences, thus shifting from "current" to more "sustainable diets" that could serve as both a climate mitigation strategy and improved population health. For these reasons, shifting to a sustainable diet has been proposed as one of the core strategies to achieve SDGs (5).

Despite these facts, reaching a sustainable diet is a complex process that requires taking several steps to consider nutrient recommendations as well as environmental, social/cultural, and economic sustainability. Figure 1 presents a conceptual framework adapted from "Guiding Principles for Sustainable Healthy Diets" developed by the FAO and the World Health Organization (WHO) (12) as a basis for this study. Based on this framework, in order to shift to a sustainable diet, various actions with respect to health, environmental, and sociocultural aspects of diet, including changing intake of different food groups, should be taken.

\section{METHODOLOGY}

\section{Identifying the Study Question}

This study aimed to answer the following questions:

- To what extent the topic of "sustainable diets" has been addressed in studies conducted in Iran?

- What is the most widely used definition of a sustainable diet in Iranian studies and which dimension of diet sustainability has been studied most?

- To what extent are diets in Iran in accordance with the principles of a sustainable diet?

- Has the issue of sustainable diet been considered/addressed in food and nutrition policies/guidelines in Iran?

- What policies and programs are needed in moving toward a sustainable diet in Iran?

\section{Identifying Relevant Studies}

We systematically searched articles related to sustainability of diet/nutrition/food system in Iran, using PubMed, Scopus, Web of science, and two Persian scientific search engines: Scientific Information Database (SID) (www.sid.ir, accessed on 15 July 2021) and Magiran (www.magiran.com, accessed on 15 July 2021).

The literature search was adapted to the databases and included the following subject heading, terms, and keywords: (carbon footprint or water footprint or land footprint or environment or sustainability or resilient or biodiverse or ecologic or life cycle analysis or global warming or climate or greenhouse gas (GHG) or greenhouse) and (food or diet or nutrition or consumption) and (Iran). We limited the search to the following dates: 1st January 1990 to 15 th July 2021 


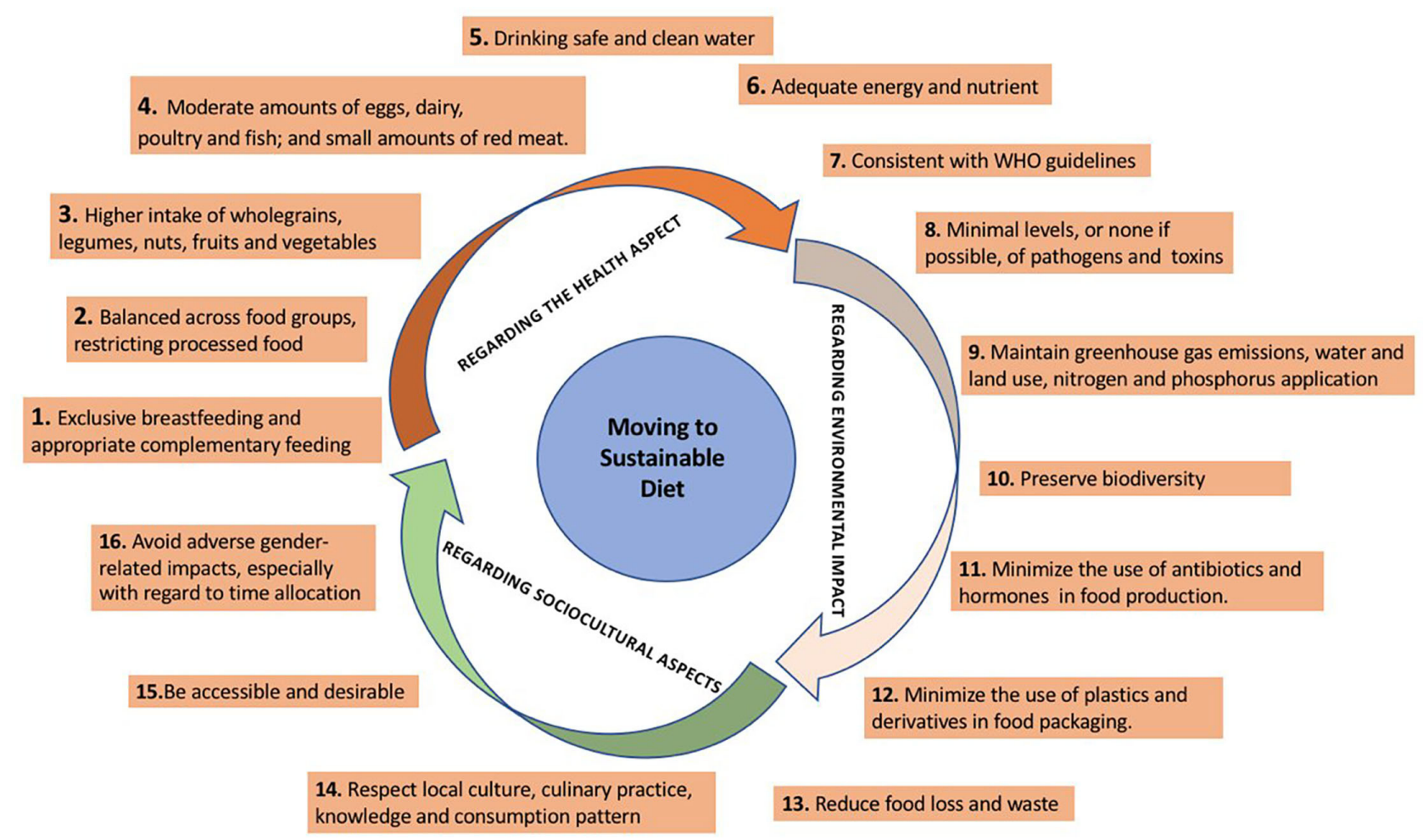

FIGURE 1 | Conceptual framework of shift to a sustainable diet (12).

and applied no language restriction. Additional references were identified by searching the gray literature and hand searching the reference lists of the included articles.

\section{Study Selection}

All the articles (in Farsi or English) that had information related to sustainable diet in Iran were included in this study. Studies that were related to sustainability issues other than food, nutrition, and/or diet or conducted in countries other than Iran were excluded. Screening of titles and abstracts was followed by fulltext screening and data extraction.

\section{Charting the Data}

The data extraction table was designed to record the following variables: year of publication, aims, food item(s)/diet, sustainability dimensions measured, changes suggested in the diet, and finding(s).

\section{Collating, Summarizing, and Reporting Results}

Included studies were reviewed and findings with respect to the questions of the study were collected and summarized. In all the stages, two of the authors (SRS and NO) held regular meetings to discuss findings and reach a consensus about the management of the findings.

\section{RESULTS}

As illustrated in the Preferred Reporting Items for Systematic Reviews and Meta-Analyses (PRISMA) diagram (Figure 2), 226 records were identified, of which 127 records were screened and excluded due to duplication. By reviewing the title and abstract, 42 records satisfied eligible criteria that were chosen for their full text to be read. Finally, 11 studies met the inclusion criteria and were included in this study (Table 1).

\section{"Sustainable Diets" Definition and Measurement in Studies in Iran}

The results indicated that "sustainable diet" is a topic that is being addressed by researchers in Iran in the recent years. Except for one study by Rahmani et al. in 2011, all the included studies had been conducted between 2017 and 2021 (13). Almost all the included studies were focused on the effect of dietary consumption change on the sustainability of diet (13, 14, 16-23), except one (15) that assessed the compliance of national nutrition policy with the sustainable diet framework. Of 10 studies on measuring sustainability dimensions of diet and changing it toward sustainability, 7 studies had focused on total dietary consumption $(13,17-20,22,23)$, one on a campus lunch menu (21), one on 14 important crops in Iran (16), and one compared the sustainability of traditional Iranian dishes with western dishes (14).

With respect to different dimensions of the sustainable diet, all the 10 studies had considered one or more of the environmental 


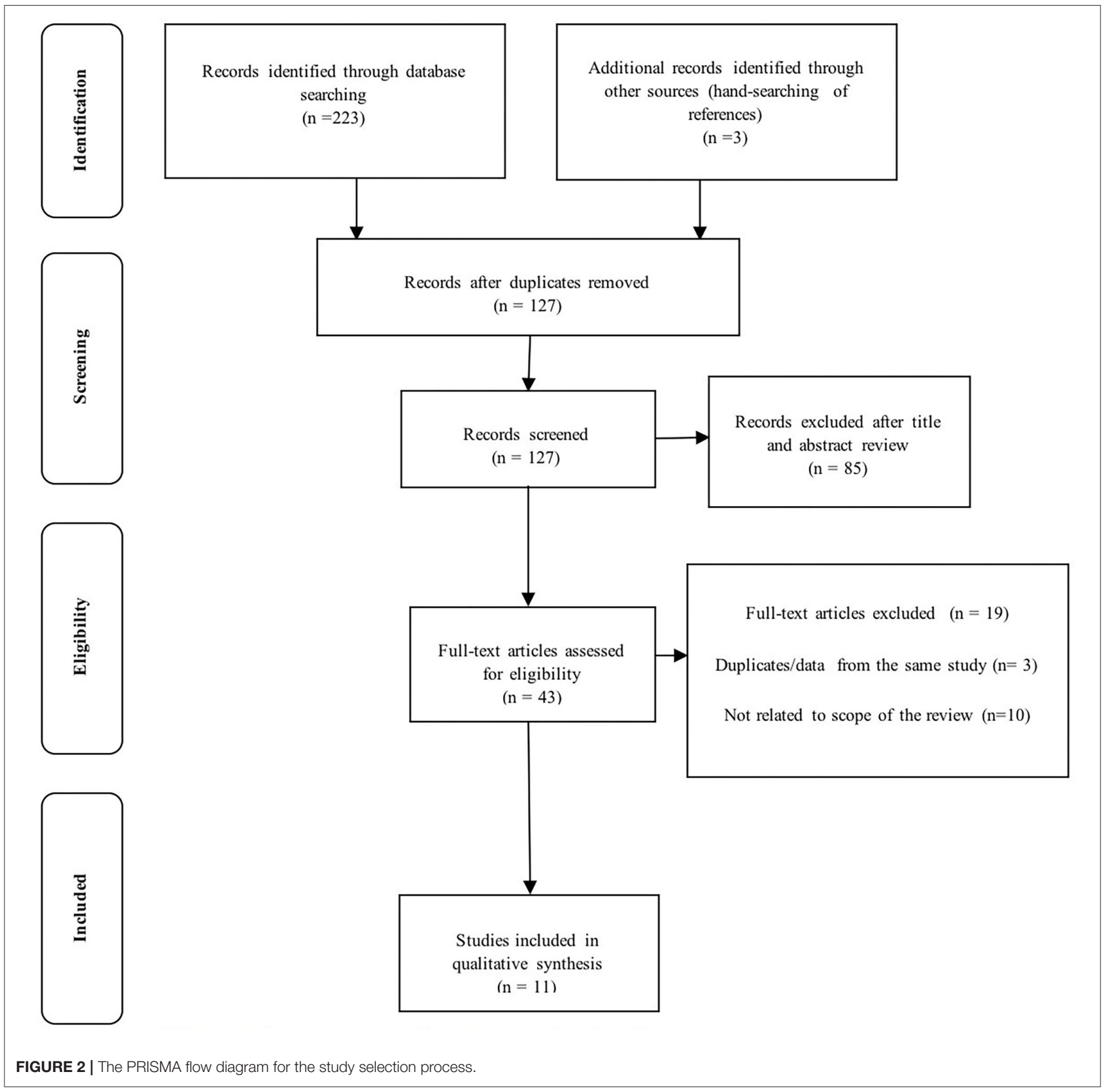

dimensions, specifically water footprint $(14,16-20,23)$ and carbon footprint $(13,14,17,20-23)$. However, energy (17) and land footprint $(21,23)$ each were measured only in one and two studies, respectively. In addition, seven studies evaluated fulfillment of nutritional recommendations (17-23) and cost and cultural acceptance of diet were considered in five $(13,17,20,21$, 23) and six (18-23) studies, respectively.

\section{Dietary Changes Required to Move Toward a Sustainable Diet in Iran}

The main approach used to identify what changes are needed to make the diet more sustainable was through comparing available data on Iranian food consumption and/or acquisition including food balance sheet data (13), household food expenditure (19, 20, 23), and food intake data $(17,18,21,22)$ with a designed and/or recommended sustainable diet. In order to design a sustainable diet, an optimizing method, i.e., linear programming (18, 19, 22), goal programming $(20,21,23)$, or a recommended reference diet $(13,17)$ was used. The included studies based on their main purpose can be classified into three groups proposing a sustainable diet: (1) to reduce carbon footprint $(13,22)$; (2) to reduce water footprint $(16,18,19)$; and (3) to fulfill nutritional, environmental, and economical 
TABLE 1 | Summary of characteristics of studies on sustainable diet in Iran (1990-2021).

\begin{tabular}{|c|c|c|c|c|c|}
\hline First author (year) & Aim & Food item(s)/diet & $\begin{array}{l}\text { Sustainable diet } \\
\text { dimension(s) } \\
\text { measured }\end{array}$ & $\begin{array}{l}\text { Suggested change(s) in } \\
\text { diet }\end{array}$ & Finding(s) \\
\hline Sobhani et. al. (15) & $\begin{array}{l}\text { To assess the compliance of } \\
\text { the Iran's National Nutrition } \\
\text { and Food Security Policy } \\
\text { (INNFSP) with the } \\
\text { components of the } \\
\text { sustainable diets framework }\end{array}$ & National policy & - & & $\begin{array}{l}\text { - The compliance of } \\
\text { the INNFSP with the } \\
\text { components of a sustainable } \\
\text { diet, without weighting } \\
\text { importance and adequacy, } \\
\text { was about } 60.32 \% \text {. The } \\
\text { score was } 60.69 \% \text { when } \\
\text { importance was weighted. } \\
\text { - The percentage of } \\
\text { compliance with the } \\
\text { components of a sustainable } \\
\text { diet was } 41.79 \% \text { when both } \\
\text { importance and adequacy } \\
\text { weighted. } \\
\text { - In order to achieve a } \\
\text { sustainable diet; which in } \\
\text { addition to providing } \\
\text { nutritional needs, has } \\
\text { environmental, cultural, and } \\
\text { economic sustainability; } \\
\text { national food and nutrition } \\
\text { policies needs to consider } \\
\text { dimensions other than } \\
\text { nutrition and health, as well. }\end{array}$ \\
\hline Kalvani et. al. (16) & $\begin{array}{l}\text { To evaluate and analyze } \\
\text { water footprint of } 14 \\
\text { important crops in Tehran } \\
\text { province and to assess their } \\
\text { water savings and losses in } \\
2008-2014 \text {. }\end{array}$ & $\begin{array}{l}\text { Apple, barley, } \\
\text { bean, grapes, } \\
\text { maize, onions, } \\
\text { oranges, potatoes, } \\
\text { rice, tomato, } \\
\text { wheat, cherry, } \\
\text { pear, peach }\end{array}$ & Water FP & $\begin{array}{l}\text { Decrease wheat/wheat } \\
\text { products }\end{array}$ & $\begin{array}{l}\text { - Wheat and rice had the } \\
\text { largest per capita water } \\
\text { footprint } \\
\text { - The consumption of wheat in } \\
\text { Iran is high (2 times larger } \\
\text { than global average). } \\
\text { - It is recommended to reduce } \\
\text { the consumption of wheat in } \\
\text { Tehran or replace it with } \\
\text { other crops. }\end{array}$ \\
\hline
\end{tabular}


TABLE 1 | Continued

\begin{tabular}{|c|c|c|c|c|c|}
\hline First author (year) & Aim & Food item(s)/diet & $\begin{array}{l}\text { Sustainable diet } \\
\text { dimension(s) } \\
\text { measured }\end{array}$ & $\begin{array}{l}\text { Suggested change(s) in } \\
\text { diet }\end{array}$ & Finding(s) \\
\hline Soltani et. al. (17) & $\begin{array}{l}\text { To investigate the role of } \\
\text { current diets and types of } \\
\text { modified diets on the need } \\
\text { for environmental resources } \\
\text { such as water, land, and } \\
\text { inputs, including nutrients, } \\
\text { energy, and greenhouse gas } \\
\text { emissions. }\end{array}$ & Total diet & $\begin{array}{l}\text { - Water FP } \\
\text { - Carbon FP } \\
\text { - Fertilizers use } \\
\text { - Cost } \\
\text { - Energy } \\
\text { - Nutritional } \\
\text { recommendation }\end{array}$ & $\begin{array}{l}\text { Decrease } \\
\text { rice }(67 \%) \text {, potato }(54 \%) \text {, } \\
\text { oil }(30 \%) \text {, sugar }(53 \%) \text {, red } \\
\text { meat }(50 \%) \text {, chicken } \\
(55 \%) \text {, egg }(48 \%) \text {, fruit } \\
(6 \%) \text {, and } \\
\text { Increase wheat flour } \\
(43 \%) \text {, legumes }(78 \%) \text {, } \\
\text { and vegetables }(32 \%)\end{array}$ & $\begin{array}{l}\text { - Plant-based diet can reduce } \\
\text { the need for blue water } \\
\text { resources by } 30 \% \text {, fertilizer } \\
\text { by } 8-12 \% \text {, energy by } \\
15 \% \text {, and greenhouse gas } \\
\text { emissions by } 10-14 \% \text {. The } \\
\text { cost of these diets are also } \\
20-24 \% \text { less; } \\
\text { - Implementing and adopting } \\
\text { sustainable plant-based } \\
\text { diets requires cultural and } \\
\text { educational efforts. }\end{array}$ \\
\hline
\end{tabular}

Sobhani et. al. (18)

\section{To assess different} scenarios to reduce water use by following healthy diet recommendations/ to suggest a healthy diet with low water FP for the Urmia population.

Mirzaie-Nodoushan et. al. (19)

Eini-Zinab et. al. (20)

Edalati et. al. (21) diet change on reducing water consumption in Iran, while meeting its nutrition requirements.
To investigate the effects of
To develope a healthy, low-cost and environmental-friendly food basket for Iran, based on current consumption

$\begin{array}{ll}\text { Total diet in Urmia } & \text { - Water FP } \\ \text { based on a FFQ } & \text { - Nutritional value } \\ & \text { - Cultural } \\ & \text { acceptance }\end{array}$

Decrease "bread, cereal, rice, and pasta" (14\%) and meats (3\%) Increase dairy (14\%) and fruits $(6 \%)$

Iranian food

basket

- Water FP

- Nutritional recommendations

- Cultural acceptance
Total diet

To analyze a canteen menu of the School of Nutrition Sciences and Food Technology sustainability and to develop a sustainable lunch menu

$\begin{array}{lll}\text { A campus lunch } & \text { - Water FP } & \text { Decrease red meat } \\ \text { menu } & \text { - Carbon FP } & \text { Increase chicken or fish } \\ & \text { - Land FP } & \text { and vegetables } \\ & \text { - Cost } & \\ & \text { - Nutritional } & \\ & \text { recommendation } & \\ & \text { - Cultural } & \\ & \text { acceptance } & \end{array}$

A healthy diet with greater proportion of energy from fruits, and lower ratio from "bread, cereal, rice, and pasta", and substitution of meats with beans can supply all recommended dietary allowances while reducing water use by $49 \%$.

These changes resulted in $7.9 \%-16.7 \%$ decrease in water footprint.
In the sustainable diet model extracted, there was a $14 \%$ reduction in total water footprint, a $14 \%$ decrease in total carbon footprint, and a $23 \%$ decrease in the cost, as well as $7 \%$ increase in NRF of diet compared with the usual consumption.

Replacing the sustainable food menu designed for Menu 1(rice-based) could decrease carbon, total water and land footprints and costs by 10,13 , 22 and $6 \%$, respectively, and increased the NRF profile by $8 \%$. Replacing the sustainable menu designed for Menu 2 (vegetable or meat-based, no rice but with wheat bread) could result in 25, 23, 27 and $28 \%$ decreases in carbon, total water and land footprints and costs, 
TABLE 1 | Continued

\begin{tabular}{|c|c|c|c|c|c|}
\hline First author (year) & Aim & Food item(s)/diet & $\begin{array}{l}\text { Sustainable diet } \\
\text { dimension(s) } \\
\text { measured }\end{array}$ & $\begin{array}{l}\text { Suggested change(s) in } \\
\text { diet }\end{array}$ & Finding(s) \\
\hline & & & & & $\begin{array}{l}\text { respectively, and increased the } \\
\text { NRF profile by } 23 \% \text {. }\end{array}$ \\
\hline $\begin{array}{l}\text { Noormohammadi et.al. } \\
\text { (22) }\end{array}$ & $\begin{array}{l}\text { To suggest dietary } \\
\text { scenarios for decreasing } \\
\text { GHG emissions }\end{array}$ & Total diet & $\begin{array}{l}\text { - } \text { Carbon FP } \\
\text { - Nutrition } \\
\text { recommendation } \\
\text { - Cultural } \\
\text { acceptance }\end{array}$ & $\begin{array}{l}\text { Decrease red and white } \\
\text { meats, eggs, grains, fats } \\
\text { and oils, and sweets } \\
\text { Increase vegetables, fruits, } \\
\text { legumes, nuts, and dairy. }\end{array}$ & $\begin{array}{l}\text { A healthy diet with a higher } \\
\text { proportion of vegetables, } \\
\text { fruits, legumes, nuts, and } \\
\text { dairy, and a lower share of } \\
\text { red and white meats, eggs, } \\
\text { grains, fats and oils, and } \\
\text { sweets can reduce carbon } \\
\text { FP by } \% 50 \text {. }\end{array}$ \\
\hline Sobhani et. al. (23) & $\begin{array}{l}\text { To evaluate the sustainability } \\
\text { of Iranian FBDG in } \\
\text { comparison with the usual } \\
\text { diet and with the selected } \\
\text { food pyramids. }\end{array}$ & Total diet & $\begin{array}{l}\text { - Water FP } \\
\text { - Carbon FP } \\
\text { - Land FP } \\
\text { - Cost } \\
\text { - Nutritional } \\
\text { recommendation } \\
\text { - Cultural } \\
\text { acceptance }\end{array}$ & $\begin{array}{l}\text { Increase legumes and } \\
\text { nuts }\end{array}$ & $\begin{array}{l}\text { - Replacing the usual dietary } \\
\text { intake of the Iranians with an } \\
\text { optimal diet based on the } \\
2016 \text { Iranian FBDG was } \\
\text { associated with reductions } \\
\text { equal to } 20.9 \% \text { for water } \\
\text { footprint, } 22.48 \% \text { for } \\
\text { carbon footprint, } 20.39 \% \\
\text { for land footprint, } 31.83 \% \\
\text { for cost, as well as } 7.64 \% \\
\text { increase in NRF index. }\end{array}$ \\
\hline
\end{tabular}

FP, footprint.

criteria $(17,20,21,23)$. Some details of the findings are as follows:

Noormohammadi et al., using linear programming, showed that compared to the usual intake (in Urmia city, in northwest Iran), a healthy diet with a higher proportion of vegetables (20\%), fruits (25\%), legumes (7\%), nuts (45\%), and dairy (115\%) and a lower share of red and white meats (92\%), eggs (70\%), grains (42\%), fats and oils, and sweets (12\%) can lead to about $50 \%$ decrease in carbon footprint. The recommended diet was nutritionally adequate, although its cost was not measured (22). Rahman et al. (13), using food balance sheet data of Iran, showed that a shift from the current diet to alternative diets, based on the WHO, the World Cancer Research Fund (WCRF), or the Mediterranean diet recommendations, will require to decrease the amount of rice, vegetables, fruits, bread, and pasta and increase comsumption of animal products. They showed that such changes will result in positive effects on economic output, while it has a negative environmental impact due to increasing carbon footprint (13). On the other hand, studies that considered carbon footprint in addition to other dimensions of the sustainable diet have shown that diets with higher consumption of vegetables, legumes, and cereals and lower contribution of red meat, rice, sugar, and egg can reduce greenhouse gas emissions by $10-14 \%$ as well as cost $(20-28 \%)$ compared to the usual $\operatorname{diet}(14,17,20,21)$.

With regard to minimizing water footprint of diet, a study by Sobhani et al., using linear programming, showed that including a greater proportion of energy from fruits (6\%) and dairy (14\%) and decreasing the energy share of bread, cereal, rice, and pasta (14\%) as well as meat, fish, poultry, and eggs (3\%) can supply all the recommended dietary allowances while reducing water use by $49 \%$ (18). Although cultural acceptance of dietary change was considered through minimizing the distance between an optimal diet with the usual diet, other environmental indicators (e.g., carbon or land footprint) or costs were not calculated. Similarly, in a study by Mirzaie-Nodoushan et al. (19), the minimized total water footprint scenario of 7.9 to $16.7 \%$ can be resulted by increasing intakes of vegetables ( $80 \%)$, milk (78-80\%), pulses (51-75\%), fish (29-80\%), eggs (37-79\%), and wheat (15-21\%) and decreasing red meat $(47 \%)$, fruits $(35-44 \%)$, poultry (9$42 \%)$, vegetable oil (13-25\%), sugar (26-30\%), and rice (17$40 \%)$. Another study that included carbon footprint and cost in addition to water footprint, nutrition recommendation, and cultural acceptance reported a $14 \%$ reduction in total water footprint (20). Soltani et al. showed that 30\% reduction in blue water footprint, i.e., surface and groundwater during the production of a product and through its supply chain can occur by following a plant-based diet (with lower rice, potato, oil, sugar, red meat, chicken, egg, and higher amount of wheat flour, legumes, and vegetables consumption compared to the usual diet) (17).

On the other hand, Edalati et al., in an attempt to design a sustainable lunch menu for a university campus in Tehran, showed that compared with the usual menu, including a higher amount of bread and vegetables while decreasing rice and red meat in the menu, it leads to $23 \%$ decrease in water footprint (21). Further, it has been shown that a higher share of bread and vegetables in traditional and local Iranian foods lead to a lower water footprint compared with western foods (14). While most studies have recommended reducing rice consumption $(18,19)$, Kalvani et al., analysis of water footprint of 14 important crops in Tehran province, recommended reducing the consumption 
of wheat, which is mainly consumed as white flat bread and suggested replacing it with other crops in order to reduce water FP (16).

A total of four studies simultaneously considered dimensions of sustainable diet including nutritional, environmental, cost, and cultural acceptability in their analysis $(17,20,21,23)$. Despite the differences in findings, almost all emphasized on higher intake of dairy $(17,20)$, vegetables $(17,20,21)$, cereals $(17,20,21)$, fruits (20), and legumes $(17,21,23)$ and in the meantime, lower intake of meat $(17,20,21)$, rice $(17,20,21)$, sugar $(17,20,21)$, fats $(17,20,21)$, and egg $(17,20,21)$ in order to have a sustainable diet. With respect to poultry consumption, there was inconsistency in the results; one study recommended higher consumption (20), while the other study emphasized reducing it (17) in order to have a more sustainable diet in Iran.

In a study by Sobhani et al., aiming at developing a healthy, low-cost, and environmentally-friendly food basket, an optimal food basket compared with the usual consumption, resulted in $14 \%$ reduction in both the total water footprint as well as total carbon footprint, $23 \%$ decrease in the cost, and $7 \%$ increase in nutrient rich foods (NRF) of diet (20). Soltani et al. suggested that a plant-based diet can reduce the need for blue water resources by $30 \%$, fertilizer by $8-12 \%$, energy by $15 \%$, and greenhouse gas emissions by $10-14 \%$. Also, the diet cost $20-24 \%$ less (17). Cultural acceptance was not considered in the latter study and this may explain the difference between its findings with those of Sobhani et al. (20). Also, the sustainable lunch menu proposed by Edalati et al. included more dishes based on chicken or fish with vegetables and fewer red meat and rice-based dishes. They showed that this change can result in decreasing carbon, total water, and land footprints as well as costs of the lunch menu by $25,23,27$, and $28 \%$, respectively, and $23 \%$ increase in its NRF profile (21).

Finally, evaluating the sustainability of the first (2005) (24) and second (2016) (25) versions of national Food-Based Dietary Guidelines (FBDGs) in Iran in comparison with the usual diet showed that while both the FBDGs have lower cost, water and carbon footprint, and higher nutritional value, the difference was statistically significant only for the more recent version. The second national FBDG emphasizes legumes and nuts by defining them as a separate food group from the meat group. Replacing the usual dietary intake of the Iranians with the optimal diet based on the last Iranian FBDG (2016) was associated with reductions equal to $20.9 \%$ for water footprint, $22.48 \%$ for carbon footprint, $20.39 \%$ for land footprint, $31.83 \%$ for cost, and $7.64 \%$ increase in NRF index (23).

\section{Considering Sustainable Diet in Food and Nutrition Policies in Iran}

No direct address to "sustainable diet" in the food and nutrition policy documents in Iran was found. However, a recent analysis on the National Food and Nutrition Security Policy compliance in Iran with the components of a sustainable diet reported a score of $60 \%$ (15). Through the mentioned policy document, some of the strategies needed to achieve a sustainable diet have been recommended including use of effective economic tools to promote healthy nutrition (e.g., sin tax, subsidies, and loans), obligatory and optional nutrient fortification of the main and complementary foods, healthy formulation of produced foods, promoting home vegetable gardens in rural areas, and distribution and supply of vegetables, fruits, and legumes in remote areas of the country through rural cooperatives to increase access of community to micronutrient resources and finally redirecting food subsidies to increase consumption of vegetables, fruits, meat, milk, and dairy products (26). Similar recommendation has been also provided by the National Action Plan for Prevention and Control of NCDs in Iran aiming at 30\% reduction in sodium/salt intake and zero amount of trans-fatty acids in oils and food products by 2025 (27). However, cost and ecological aspects of diet were not taken into account in both the documents.

\section{DISCUSSION}

"Sustainable diets" are not mentioned directly and clearly in the SDGs; however, according to the post-2020 global biodiversity framework, in achieving the vision of "living in harmony with nature," shifting toward a sustainable diet is one of the key actions required (28). This study is an attempt undertaken to summarize current literature on the sustainability of the Iranian diet in order to inform decision-makers on changes required to dietary guidelines and policies to be both nutritionally adequate and environmentally sustainable and to identify potential trade-offs.

In Iran, given the fact that there is low intake of vegetables, fruits, and dairy (29), a large share of food in the household budget (about 24\%) (30) and an increasing trend of water shortage (31), $\mathrm{CO}_{2}$ emission (32), and warmer climate (33) during the recent years, moving toward a sustainable diet, is inevitable. The findings of this study showed that an increase in dairy, fruits, vegetables, cereals, poultry, and legumes consumption and a decrease in intake of bread, rice and pasta, red meat, eggs, fats, sugar, and sweets are the main changes being suggested in the Iranian diet in order to move it toward sustainablility. These findings are in line with the EAT-Lancet recommendation that emphasizes a diet rich in plant-based foods with fewer animal sources in order to both improve the health and benefit of the environment (4). The specific recommendations identified with respect to the required changes in the Iranian diet are as follows:

First, the need for consuming higher amounts of varied fruits and vegetables as a step toward a sustainable diet was reconfirmed in this study. Sustainable diets are characterized by varied and high amounts of vegetables and fruits (34), which make them more nutritious and environmentally friendly, with a lower risk of chronic diseases compared to other dietary patterns (35). Vieux et al. investigating changes needed to improve sustainability of the diet across Europe and concluded that this can be achieved by substituting food items from the sugar/fat/alcohol group with fruits, vegetables, and starches in "the diet" (36). It is worth noting that consumption of fruit and vegetables in Iran has been consistently reported to be lower than minimum recommended amount of $400 \mathrm{~g}$ per capita per day by 
the WHO $(29,37)$. Lack of access to fruits and vegetables in all the regions and in all the seasons of the year, high price of fruits in particular, and the high loss and waste rate of these products are the identified reasons behind insufficient intake of these food groups in Iran (38).

Second, reducing red meat consumption and substituting it with legumes (plant sources of proteins) or poultry in the Iranian diet is another recommendation that has been raised by the studies on sustainable diet in Iran. Since 1960s, consumption of animal-based foods has increased throughout the world due to rising global average income, higher standards of living, and increased efficiency of production (35). Similarly, the share of meat in the Iranian food basket has increased over the past 30 years; although in the recent years, due to the economic crises of country, the increase rate has slowed down (29). Bahn et al. had previously proposed that reducing red meat consumption and simultaneously increasing consumption of vegetables/beans in Middle East and North Africa (MENA) countries can result in positive environmental effects (39). Considering higher water and carbon footprint, energy input, fertilizer, and pesticide use with an animal-based diet compared with a plant-based diet (35), low-to-moderate consumption of seafood and poultry and zero to low consumption of red meat and processed meat are recommended in order to have a sustainable diet (4). With lower water Footprint (FP) and price of poultry compared to red meat, it seems poultry is a more realistic choice $(40,41)$. Fish is anoter alternative, which is not much emphasized in Iranian population due to its higher price and low desirability in the majority of Iranians (it is highly desirable in North and South of Iran). Average consumption of fish in the Iranian diet (8 g/day) (29) is way below the recommended amount of $30 \mathrm{~g} /$ day (42).

Another suitable alternative to red meat is legumes. Legumes are inexpensive and sustainable sources of protein with low carbon and water FP that are part of the traditional diets in most cultures including Iran (43). Based on a study by Roos et al., reducing daily per capita intake of meat from 110 to $55 \mathrm{~g}$ and replacing it with $50 \mathrm{~g}$ of beans is associated with a $20 \%$ reduction in environmental footprint (44). Besides, legumes production positively affects soil quality, biodiversity, and enriches the soil through nitrogen fixation (45). The role of legumes in achieving a sustainable diet is so important that the FAO designated 2016 as the year of pulses as a subgroup of legumes and introduced it as food crops that can play a major role in addressing future global food security and environmental challenges as well as contributing to healthy diets (46). For these reasons, in the second version of FBDG in Iran (2016), legumes and nuts have been defined as a separate food group from the meat group. Comparing the sustainability dimensions of the first and second FBDGs of the country showed that the recent version can result in a diet with lower cost, water, and carbon footprint, provides higher nutritional value, and can be more in line with a sustainable diet compared to the previous version (2005) (23).

Third, replacing refined carbohydrates (e.g., white bread, polished/white rice) with whole-grain products is another required step identified to move toward a sustainable diet in Iran. White rice and white flat bread are the main staple foods in the Iranian diet, the share of the latter being higher among those with lower income (47). Iran is the 13th biggest white rice consumer worldwide (47) with an annual consumption of $36.6 \mathrm{~kg}$ per capita, which is 7 times more than the European Union (5.3 kg per capita) (48). Higher white rice and bread intake are associated with an increased risk of type 2 diabetes $(49,50)$. Besides, wheat and rice have the largest per capita water FP in the country (16). It should be noted that water FP varies for each crop depending on irrigation and on average rice cultivation has the least water efficiency (51). Studies on the sustainable diet in China also showed that a decrease in rice consumption is required due to its role as the largest contributor to reductions in GHG emissions (52). Promotion of less refined and polished rice or wheat will require policy change at the production level as well as consumer education.

The fourth recommendation identified through this study in order to have a more sustainable diet is decreasing sugar and fats. Consumption of oils and sugar by Iranian is 20 and $38 \%$ of daily energy intake, respectively, which is higher than the recommended amounts (53). Since 1960s, due to the improvement of vegetable oil production technology and increased supply, its price has decreased worldwide (54). Also, the increased supply of processed foods and sweetened beverages has resulted in higher intake of sugars (55). Despite low environmental impact of sugar and fat consumption, considering their negative impact on health and prevention of NCDs (37), the need for reducing their intake to $31 \mathrm{~g} /$ day for added sugar and 40 $\mathrm{g} /$ day for added fats has been emphasized (4).

The final recommendation is the only one that seems differerent with the EAT-Lancet recommendation of decreasing dairy products; however, due to very low consumption of dairy products in Iran (168 g/day) (27), there is a need to increase the consumption of this food group in order to comply with the recommendation of $250 \mathrm{~g} /$ day (29). In fact, the average consumption level of dairy products in Iran is less than half the recommended level and has had a decreasing trend due to a drastic rise in the price over the last decade as a result of inflation and poor governmental support policies (56). Similarly, Donati et al. have recommended increasing dairy as part of the changes required to achieve a more sustainable diet in adolescents in Italy (57).

Based on this study, there is no clear and direct reference to sustainable diet in the related documents in Iran and there is no consistent approach with respect to the policies and strategies to move toward a sustainable food and nutrition system in policy documents in Iran. In one hand, the food production policies of country have been more focused on increasing agricultural production aiming at self-sufficiency and sustainable agriculture with less attention to the quality and sustainability of the food consumed, i.e., sustainable diet (58). On the other hand, due to the high prevalence of NCDs, the health sector has properly focused on health aspect of a sustainable diet through investment on policies and strategies to decrease the amount of sugar, salt, and fat (specifically trans-fatty acids) in the Iranian diet. The National Action Plan for Prevention and Control of NCDs in Iran has strongly focused on reducing sodium/salt intake as well as saturated and trans-fatty acids in oils by 2025 (27). In line with these policies, several regulatory policies/programs have been 
TABLE 2 | Regional recommended strategies for a sustainable food diet, current status of related policies in Iran, and recommended actions.

\begin{tabular}{|c|c|c|c|}
\hline $\begin{array}{l}\text { "Game changing" food } \\
\text { systems actions (68) }\end{array}$ & $\begin{array}{l}\text { Recommended priority } \\
\text { actions } 2020-2030\end{array}$ & Existing policies in Iran & $\begin{array}{l}\text { Gap/recommended policies } \\
\text { for Iran }\end{array}$ \\
\hline $\begin{array}{l}\text { Fiscal policies for healthy } \\
\text { and sustainable diets. }\end{array}$ & $\begin{array}{l}\text { - Implement a tax on } \\
\text { sugar-sweetened beverages } \\
\text { and use other taxes and } \\
\text { subsidies to promote healthy } \\
\text { diets }\end{array}$ & $\begin{array}{l}\text { 2015: A maximum tax of } 10 \% \text { was imposed to } \\
\text { unhealthy food (63). } \\
\text { - The Iranian budget law for the fiscal year } \\
\text { 2013-2014 obligated the government to taxation } \\
\text { of soft drink at rate of } 15 \text { and } 20 \% \text { for locally }\end{array}$ & $\begin{array}{l}\text { Elimination of subsidies on } \\
\text { vegetable oil and sugar and } \\
\text { instead shifting subsidies to } \\
\text { healthier foodstuffs (i.e, fruits, } \\
\text { vegetables and dairy) (71). }\end{array}$ \\
\hline
\end{tabular}

Public food procurement and service policies for a healthy diet sustainably produced

Regulation of marketing of foods and non-alcoholic beverages, including breastmilk substitutes
Food products reformulation

Front-of-pack labeling

Food fortification
- Review food subsidy programs and progressively eliminate subsidies for all types of fats/oils and sugar.

- Introduce and enforce mandatory guidelines for provision of healthy food in public institutions (e.g., schools, hospitals, military, prison and other government institutions).

- Implement the WHO Set of recommendations on marketing of foods and non-alcoholic beverages to children

- Reinforce the package of policies and interventions to promote, protect and support breastfeeding and appropriate complementary feeding.

- Progressively reduce intakes of salt, sugars and saturated fats by improving the nutritional quality of foods through government-led reformulation programmes.

- Eliminate trans fats through the development of legislation to ban the use of industrially-produced trans fats in the food chain produced and imported goods, respectively (63).

- 2010: Subsidy on sugar and vegetable oil were reduced (69).

- 2014: Eliminating subsidies for milk. (70)

- 2005: The National FBDGs was developed and introduces as one of the main tools to raise awareness regarding healthy diet. Second version of the FBDG was introduced in 2016 (24).

- 1995: Code of marketing of the breast milk substitutes was initiated in the country (72).

- The 5th national develoment plan (2011-2016), bans advertising unhealthy goods and services to the public (63).

- 2014: Healthy school canteen program was initiated to regulate access to healthy foods in schools (73).

- 1978: Food advertisements in school and educational facilities are banned (74).

- 2015: Mandatory upper limit of salt in most commonly consumed canned foods e.g., tomato paste and salty snacks, and all types of bread was decreased (1.8\%) (59). Also, the standard of salt in cheese was decreased from 4 to $3 \%$ and in dough (fermented yogurt drink) was decreased from 1 to $0.8 \%$ (59).

- 2016-2017: The standard of salt in bread was further decreased to 1\% (59).

- 2017: The standard of SFA in edible oil decreased to $<25$ (59).

- 2018: Salt use in probiotic yogurts was banned (59).

- Food reformulation initiatives for reducing the amount of sugar, salt, and fat, specifically the industrially-produced trans-fatty acids in industrial food products $(61,62)$.

- 2014: MOHME launched Front-of-Pack nutrition labeling policy (as traffic light scheme) with the objective of reducing sodium, trans fatty acid and sugar intake in accordance with the national action plan for control and prevention of NCDs (63).

- Mandatory flour fortification with iron and folic acid was implemented in one province from 2001 and expanded simultaneously to the other provinces in Iran (80).

- since 2000, Iran has been recognized by WHO-as an IDD free nation through integration of IDD control into the health network and mandatory iodization of household salt (81).

- Voluntary fortification of edible oil, milk, cakes, and pasta with vitamin D (82).
Reevaluating the national FBDG, as well as the thrift food basket in terms of food grouping and recommendations in order to make it more sustainable.

"Water penalty" and the "water tax" for food products with high water footprint (75). Eliminate legal barriers and disproportionate food-safety standards that lead to high waste rates (71). Investments in water-friendly food processing technologies to tackle natural resources overexploitation and promote corporate profitability (75).

Decrasing flour milling degree to incease fiber and nutrient content of flour and bread (76). Focus on some of the new technologies being developed to create alternatives to animal products, such as meat, milk and egg, which should reduce the amount of meat consumed. Also, increasing number of fiber-containing products is highly recommended $(77,78)$.

Food labels including information about links between food and climate chang are effective in encouraging sustainable food choices (79)

Universal fortification along with small dietary shifts represents an approach to improve the vitamin D status of the general population, at a high acceptability without affecting the carbon footprint (83) 
implemented to tackle NCDs, e.g., setting a mandatory upper limit of salt in bread $(59,60)$, food reformulation initiatives for reducing the amount of sugar, salt, and fat, specifically the industrially-produced trans-fatty acids in industrial food products $(61,62)$, sin tax policy on increasing the price of sugarsweetened beverages (SSB) (63), traffic light nutrition labeling for more than $80 \%$ of the manufactured food products (64), and educational interventions/campaigns to improve awareness and food choices of consumers (65). In addition, the national FBDG, as one of the main tools to raise awareness with respect to appropriate and healthy diet, has been in place since 2005 (24). However, within all these policies, there is a gap in adressing ecological aspects of a sustainable diet (e.g., water, land, and carbon footprints) with a specific reference to context of Iran. Recently, there have been attempts to evaluate all the dimensions of sustainablility of Iran FBDG (23) to pave the ground for a sustainable FBDG in the close future.

One other aspect that is almost ignored in study with respect to sustainable diet in Iran is measurement and interventions with respect to food loss and waste. There are different estimations of the amount of waste and loss of agricultural products in Iran, ranging from 18.5 up to about 35\% (66). A report by the Food Producers Cooperatives of Iran indicates that out of about 130 million tons of foods being produces in Iran, 25 million tons are lost (67). According to the study conducted by Fami et al. in Tehran, every consumer wastes about $27 \mathrm{~kg}$ of edible food annually (66). A total of seven food items identified with the highest amount of waste at household level are bread, cooked rice, cooked pasta, fresh fruits, fresh vegetables, salads, milk, and dairy products (66). Developement of proper infrastructure and skills to decrease the loss at the production and distribution levels as well as improving knowledge and skills on planning, preparation, and storage, and raising awareness about values and consequences of avoiding food waste at the procurement and consumption levels (66) can lead to decrease food loss and food waste.

Table 2 presents the current policies across the food system that support move toward a sustainable diet in Iran, based on the available recommendations (68) as well as gaps and recommended policies to improve current efforts.

To the best of our knowledge, this study is the first study on current literature on the sustainability of the Iranian diet

\section{REFERENCES}

1. Popkin BM. Technology, transport, globalization and the nutrition transition food policy. Food Policy. (2006) 31:554-69. doi: 10.1016/j.foodpol.2006. 02.008

2. Kearney J. Food consumption trends and drivers. Philos Trans R Soc Lond B Biol Sci. (2010) 365:2793-807. doi: 10.1098/rstb.2010.0149

3. Searchinger T, Waite R, Hanson C, Ranganathan J, Dumas P, Matthews E, et al. Creating a sustainable food future: a menu of solutions to feed nearly 10 billion people by 2050. Final report. Washington, D.C.:WRI (2019).

4. Willett W, Rockström J, Loken B, Springmann M, Lang T, Vermeulen $\mathrm{S}$, et al. Food in the Anthropocene: the EAT-Lancet Commission on healthy diets from sustainable food systems. Lancet. (2019) 393:44792. doi: 10.1016/S0140-6736(18)31788-4 and recommended changes. The findings can serve to guide policymakers and planners of the food and nutrition food system to develop and implement policies to shift to a sustainable dietary pattern in Iranian population. This study also has several limitations that need to be considered in evaluating its findings. The quality of the studies included in this study was not assessed. Thus, the conclusions are based on the existence of studies rather than their intrinsic quality. Moreover, the Iranian food intake values based on a nutritional assessment were not available for comparison with the recommended values.

\section{CONCLUSION}

This study showed that there is an urgent need to accelerate the move toward a sustainable diet in Iran. For this purpose, increasing consumption of dairy, fruits, vegetables, cereals, poultry, and legumes and decreasing bread, rice and pasta, red meat, eggs, hydrogenated fats, sugar, and sweets intake are the main changes suggested. Development of an enabling environment to promote moving toward a sustainable diet will require policy and action to: (1) Improve public awareness and interest; (2) Support study to provide evidence and identify possible alternatives; and (3) Plan and implement interventions/programs to promote and facilitate healthy and sustainable diets. In this regard, defining scientific targets to achieve sustainable diet and food production and re-evaluating existing policies related to food and nutrition system are prerequisites to such transformation.

\section{AUTHOR CONTRIBUTIONS}

$\mathrm{NO}$ and AA contribute to the conceptualization. SS and NO contribute to the data collection, reviewing the studies, analyses, and writing-original draft preparation. NO, ZA, and AA contribute to the writing-review and editing. All the authors have read and agreed to the published version of the manuscript.

\section{ACKNOWLEDGMENTS}

The authors gratefully acknowledge support from the WHO office in the Eastern Mediterranean region.

5. Gold K, McBurney RP. Conservation of plant diversity for sustainable diets. In: Sustainable Diets and Biodiversity-Directions and Solutions for Policy, Research and Action. Rome: FAO Headquarters (2012).

6. Tokunaga M, Takahashi T, B Singh R, Rupini D, Toda E, Nakamura T, et al. Diet, nutrients and noncommunicable diseases. Open Nutraceuticals J. (2012) 5:146-59. doi: 10.2174/1876396001205010146

7. Krishnaswamy K, Gayathri R. Nature's bountiful gift to humankind: vegetables \& fruits \& their role in cardiovascular disease \& diabetes. Indian J Med Res. (2018) 148:569. doi: 10.4103/ijmr.IJMR_1780_18

8. Aleksandrowicz L, Green R, Joy E, Smith P, Haines A. The impacts of adopting environmentally sustainable and healthy diets on greenhouse gas emissions, land use, and water use: a systematic review. PLoS ONE. (2016) 11:e0165797. doi: 10.1371/journal.pone.0165797 
9. Perignon M, Vieux F, Soler L-G, Masset G, Darmon N. Improving diet sustainability through evolution of food choices: review of epidemiological studies on the environmental impact of diets. Nutr Rev. (2017) 75:217. doi: 10.1093/nutrit/nuw043

10. Misra AK. Climate change and challenges of water and food security. Int $J$ Sustain Built Environ. (2014) 3:153-65. doi: 10.1016/j.ijsbe.2014.04.006

11. Kelishadi R, Alikhani S, Delavari A, Alaedini F, Safaie A, Hojatzadeh E. Obesity and associated lifestyle behaviours in Iran: findings from the first national non-communicable disease risk factor surveillance survey. Public Health Nutr. (2008) 11:246-51. doi: 10.1017/S1368980007000262

12. World Health Organization. Sustainable Healthy Diets: Guiding Principles. Rome: Food \& Agriculture Org (2019).

13. Rahmani R, Bakhshoodeh M, Zibaei M, Heijman W, Eftekhari MH. Economic and environmental impacts of dietary changes in Iran: an input-output analysis. Int J Food Syst Dyn. (2011) 2:447-63. doi: 10.18461/ijfsd.v2i4.248

14. Eini-Zinab H, Sobhani R. Sustainable diets and traditional local foods. Iran J Nutr Sci Food Technol. (2017) 12:S151-8. Available online at: https://nsft. sbmu.ac.ir/article-1-2630-fa.pdf (accessed June, 2021).

15. Sobhani S, Sheikhi M, Eini-Zinab H, Mohammadi-Nasrabadi F. Compliance of Iran's national nutrition and food security policy (2012-2020) with components of sustainable diets framework. Iran J Nutr Sci Food Technol. (2018) 13:153-60.

16. Kalvani SR, Sharaai A, Manaf L, Hamidian A. Evaluation of water footprint of selected crop consumption in Tehran Province. Appl Ecol Environ Research. (2019) 17:11033-44. doi: 10.21837/pm.v17i10.634

17. Soltani E, Soltani A, Alimagham M, Eskandar Z. Diet and its Role in the Necessary Resources for Agricultural Production. Gorgan: Gorgan University of Agricultural Sciences and Natural Resources (2019).

18. Sobhani SR, Rezazadeh A, Omidvar N, Eini-Zinab H. Healthy diet: a step toward a sustainable diet by reducing water footprint. J Sci Food Agric. (2019) 99:3769-75. doi: 10.1002/jsfa.9591

19. Mirzaie-Nodoushan F, Morid S, Dehghanisanij H. Reducing water footprints through healthy and reasonable changes in diet and imported products. Sustain Prod Consumption. (2020) 23:30-41. doi: 10.1016/j.spc.2020.04.002

20. Eini-Zinab H, Sobhani SR, Rezazadeh A. Designing a healthy, low-cost and environmentally sustainable food basket: an optimisation study. Public Health Nutr. (2021) 24:1952-61. doi: 10.1017/S1368980020003729

21. Edalati S. .Sobhani R, Fallah F, Renani MM, Tavakoli S, .Nazari H, et al. Analysis of a campus lunch menu for aspects of sustainable diets and designing a sustainable lunch menu. Iran J Nutr Sci Food Technol. (2021) 16:37-46. doi: 10.52547/nsft.16.1.37

22. Noormohammadi M, Eini-Zinab H, Rezazadeh A, Omidvar N, Sobhani SR. A step toward a sustainable diet by reducing carbon footprint: a case study in Iran. J Environ Health Sustain Develop. (2021) 6:1423-32.

23. Sobhani SR, Edalati S, Eini-Zinab H, Kennedy G, Omidvar N, A. comparative analysis of sustainability of the usual food intakes of the Iranian population, Iranian food based dietary guidelines and optimized dietary models. unpublished. (2021).

24. Montagnese C, Santarpia L, Iavarone F, Strangio F, Sangiovanni B, Buonifacio $\mathrm{M}$, et al. Food-based dietary guidelines around the world: eastern Mediterranean and Middle Eastern countries. Nutrients. (2019) 11:1325. doi: 10.3390/nu11061325

25. Safavi S, Omidvar N, Djazayery A, Minaie M, Hooshiarrad A, Sheikoleslam R. Development of food-based dietary guidelines for Iran: a preliminary report. Ann Nutr Metab. (2007) 51:32-5. doi: 10.1159/000103565

26. Damari B, Abdollahi Z, Hajifaraji M, Rezazadeh A. Nutrition and food security policy in the Islamic Republic of Iran: situation analysis and roadmap towards 2021. East Mediterr Health J. (2018) 24:177-88. doi: 10.26719/2018.24.2.177

27. Ghazizadeh-Hashemi S, Larijani B. National Action Plan for Prevention and Control of Non Communicable Diseases and the Related Risk Factors in the Islamic Republic of Iran, 2015-2025. Tehran, Iran: Aftab e Andisheh Publications (2015). p. 47-65.

28. Delabre I, Rodriguez LO, Smallwood JM, Scharlemann JP, Alcamo J, Antonarakis AS, et al. Actions on sustainable food production and consumption for the post-2020 global biodiversity framework. Sci Adv. (2021) 7:eabc8259. doi: 10.1126/sciadv.abc8259

29. Sobhani SR, Eini-Zinab H, Rezazadeh A. Assessing the changes in Iranian household food basket using national household budget and expenditure survey data, 1991-2017. Int J Prev Med. (2021) 12:148-57. doi: 10.4103/ijpvm.IJPVM_404_19

30. Central Bank of the Islamic Republic of Iran. The Household Budget Survey in Urban Area. Central Bank of the Islamic Republic of Iran (2016) 1:8-10.

31. Zarghami M, Abdi A, Babaeian I, Hassanzadeh Y, Kanani R. Impacts of climate change on runoffs in East Azerbaijan, Iran. Glob Planet Change. (2011) 78:137-46. doi: 10.1016/j.gloplacha.2011.06.003

32. Lotfalipour MR, Falahi MA, Ashena M. Economic growth, CO2 emissions, and fossil fuels consumption in Iran. Energy. (2010) 35:5115-20. doi: 10.1016/j.energy.2010.08.004

33. Tabari H, Somee BS, Zadeh MR. Testing for long-term trends in climatic variables in Iran. Atmos Res. (2011) 100:13240. doi: 10.1016/j.atmosres.2011.01.005

34. Shifting to Sustainable Diets: United Nations. Available from: https://www.un. org/en/academic-impact/shifting-sustainable-diets

35. Reynolds CJ, Buckley JD, Weinstein P, Boland J. Are the dietary guidelines for meat, fat, fruit and vegetable consumption appropriate for environmental sustainability? A review of the literature. Nutrients. (2014) 6:225165. doi: 10.3390/nu6062251

36. Vieux F, Perignon M, Gazan R, Darmon N. Dietary changes needed to improve diet sustainability: are they similar across Europe? Eur J Clin Nutr. (2018) 72:951-60. doi: 10.1038/s41430-017-0080-z

37. World Health Organization. Diet, Nutrition, and the Prevention of Chronic Diseases: Report of a Joint WHO/FAO Expert Consultation. Geneva: World Health Organization (2003).

38. Mason-D'Croz D, Bogard JR, Sulser TB, Cenacchi N, Dunston S, Herrero M, et al. Gaps between fruit and vegetable production, demand, and recommended consumption at global and national levels: an integrated modelling study. Lancet Planet Health. (2019) 3:e318-29. doi: 10.1016/S2542-5196(19) 30095-6

39. Bahn R, Labban SE. Hwalla N. Impacts of shifting to healthier food consumption patterns on environmental sustainability in MENA countries. Sustain Sci. (2019) 14:1131-46. doi: 10.1007/s11625-018-0600-3

40. Statistical Center of Iran Household, Expenditure and Income. Available from: https://www.amar.org.ir/english/Metadata/Statistical-Survey/HouseholdExpenditure-and-Income (accessed June 2020)

41. Mekonnen MM, Hoekstra AY. A global assessment of the water footprint of farm animal products. Ecosystems. (2012) 15:401-15. doi: 10.1007/s10021-011-9517-8

42. Nesheim MC, Oria M, Yih PT. Dietary recommendations for fish consumption. In: A Framework for Assessing Effects of the Food System. US: National Academies Press. (2015).

43. Semba RD, Ramsing R, Rahman N, Kraemer K, Bloem MW. Legumes as a sustainable source of protein in human diets. Global Food Security. (2021) 28:100520. doi: 10.1016/j.gfs.2021.100520

44. Röös E, Carlsson G, Ferawati F, Hefni M, Stephan A, Tidåker P, et al. Less meat, more legumes: prospects and challenges in the transition toward sustainable diets in Sweden. Renew Agri Food Syst. (2020) 35:192205. doi: 10.1017/S1742170518000443

45. Meena RS, Das A, Yadav GS, Lal R. Legumes for Soil Health and Sustainable Management. Germany: Springer (2018). doi: 10.1007/978-981-13-0253-4

46. Calles T. The international year of pulses: what are they and why are they important. Agri Develop. (2016) 26:40-2. Available online at: http://www.fao. org/3/a-bl797e.pdf (accessed June, 2021).

47. Golozar A, Khalili D, Etemadi A, Poustchi H, Fazeltabar A, Hosseini F, et al. White rice intake and incidence of type- 2 diabetes: analysis of two prospective cohort studies from Iran. BMC Public Health. (2017) 17:111. doi: 10.1186/s12889-016-3999-4

48. Jifroudi S, Teimoury E, Barzinpour F. Designing and planning a rice supply chain: a case study for Iran farmlands. Decis Sci Lett. (2020) 9:16380. doi: $10.5267 /$ j.dsl.2020.1.001

49. Aune D, Norat T, Romundstad P, Vatten LJ. Whole grain and refined grain consumption and the risk of type 2 diabetes: a systematic review and doseresponse meta-analysis of cohort studies. Eur J Epidemiol. (2013) 28:84558. doi: 10.1007/s10654-013-9852-5

50. Hu EA, Pan A, Malik V, Sun Q. White rice consumption and risk of type 2 diabetes: meta-analysis and systematic review. BMJ. (2012) 344:e1454. doi: 10.1136/bmj.e1454 
51. Friel S, Barosh LJ, Lawrence M. Towards healthy and sustainable food consumption: an Australian case study. Public Health Nutr. (2014) 17:115666. doi: $10.1017 / \mathrm{S} 1368980013001523$

52. Song G, Li M. Fullana-i-Palmer P, Williamson D, Wang Y. Dietary changes to mitigate climate change and benefit public health in China. Sci Total Environ. (2017) 577:289-98. doi: 10.1016/j.scitotenv.2016.10.184

53. Abdi F, Atarodi KZ, Mirmiran P, Esteki T. Surveying Global and Iranian Food Consumption Patterns: A Review of the Literature (2015).

54. Hawkes C. Uneven dietary development: linking the policies and processes of globalization with the nutrition transition, obesity and diet-related chronic diseases. Global Health. (2006) 2:1-18. doi: 10.1186/1744-8603-2-4

55. Wittekind A, Walton J. Worldwide trends in dietary sugars intake. Nutr Res Rev. (2014) 27:330-45. doi: 10.1017/S0954422414000237

56. Rahnama H, Rajabpour S. Factors for consumer choice of dairy products in Iran. Appetite. (2017) 111:46-55. doi: 10.1016/j.appet.2016.12.004

57. Donati M, Menozzi D, Zighetti C, Rosi A, Zinetti A, Scazzina F. Towards a sustainable diet combining economic, environmental and nutritional objectives. Appetite. (2016) 106:48-57. doi: 10.1016/j.appet.2016.02.151

58. Soltani A, Alimagham S, Nehbandani A, Torabi B, Zeinali E, Zand E, et al. Future food self-sufficiency in Iran: a model-based analysis. Global Food Secur. (2020) 24:100351. doi: 10.1016/j.gfs.2020.100351

59. Al-Jawaldeh A, Taktouk M, Chatila A, Naalbandian S, Al-Thani A-AM, Alkhalaf MM, et al. Salt reduction initiatives in the Eastern Mediterranean region and evaluation of progress towards the 2025 global target: a systematic review. Nutrients. (2021) 13:2676. doi: 10.3390/nu13082676

60. Al Jawaldeh A, Al-Khamaiseh M. Assessment of salt concentration in bread commonly consumed in the Eastern Mediterranean Region. East Mediterr Health J. (2018) 24:18-24. doi: 10.26719/2018.24.1.18

61. Amini M, Doustmohammadian A, Ranjbar M. Dietary Risk Reduction Projects in Industrial Foods in Iran. SRPH Journal of Fundamental Sciences and Technology. (2021) 3:1-4.

62. Schafer M, de Figueiredo MD, Iran S, Jaeger-Erben M, Silva ME, Lazaro JC, et al. Imitation, adaptation, or local emergency? - A cross-country comparison of social innovations for sustainable consumption in Brazil, Germany, and Iran. J Cleaner Prod. (2021) 284:124740. doi: 10.1016/j.jclepro.2020.124740

63. Zargaraan A, Dinarvand R, Hosseini H. Nutritional traffic light labeling and taxation on unhealthy food products in Iran: health policies to prevent non-communicable diseases. Iran Red Crescent Med J. (2017) 19:e57874. doi: 10.5812/ircmj.57874

64. Edalati S, Omidvar N, Haghighian Roudsari A, Ghodsi D, Zargaraan A. Development and implementation of nutrition labelling in Iran: A retrospective policy analysis. Int J Health Plann Manage. (2020) 35:e2844. doi: 10.1002/hpm.2924

65. Abdollahi Z, Sayyari A-A, Olang B, Ziaodini H, Fallah H, Abasalti Z, et al. Effect of educational intervention on healthy lifestyle in Iranian children and adolescents: the IRAN-Ending Childhood Obesity (IRAN-ECHO) program. J Nutr Sci Diet. (2019) 5:32-9. doi: 10.18502/jnsd.v5i1.5234

66. Fami HS, Aramyan LH, Sijtsema SJ, Alambaigi A. Determinants of household food waste behavior in Tehran city: a structural model. Resour Conserv Recycling. (2019) 143:154-66. doi: 10.1016/j.resconrec.2018.12.033

67. FinancialTribune, 2017. Iran's Annual Food Waste at $25 \mathrm{~m}$ Tons. Available from: https://nancialtribune.com/articles/economy-domestic-economy/ 70344/iran-s-annual-food-waste-at-25m-tons

68. Al-Jawaldeh A, McColl K. Shifting to healthy and sustainable consumption patterns in the Eastern Mediterranean Region. Unpublished. (2021).

69. Hosseini SS, Charvadeh MP, Salami H, Flora C. The impact of the targeted subsidies policy on household food security in urban areas in Iran. Cities. (2017) 63:110-7. doi: 10.1016/j.cities.2017.01.003

70. Mohammadi-Nasrabadi F, Omidvar N, Khoshfetrat MR, Kolahdooz F. Assessment and Analysis of Food Market in the Recent Decade in Iran (from 2005 to 2014). Tehran, Iran: National Nutrition and Food Technology Research Institute (2019).

71. Reisch L, Eberle U, Lorek S. Sustainable food consumption: an overview of contemporary issues and policies. Sustain Sci Pract Policy. (2013) 9:725. doi: 10.1080/15487733.2013.11908111

72. Al Jawaldeh A, Sayed G. Implementation of the international code of marketing of breast-milk substitutes in the Eastern Mediterranean Region. East Mediterr Health J. (2018) 24:25-32. doi: 10.26719/2018.24.1.25

73. Omidvar N, Babashahi M, Abdollahi Z, Al-Jawaldeh A. Enabling food environment in kindergartens and schools in iran for promoting healthy diet: is it on the right track? Int J Environ Res Public Health. (2021) 18:4114. doi: 10.3390/ijerph18084114

74. The Islamic Revolution Assembly. The Regulation on the Establishment and Monitoring of the Work and Activity of Advertising Centers. Tehran, Iran: The Islamic Revolution Assembly (1978).

75. Tsolakis N, Srai JS, Aivazidou E. Blue water footprint management in a UK poultry supply chain under environmental regulatory constraints. Sustainability. (2018) 10:625. doi: 10.3390/su10030625

76. Miller DD, Welch RM. Food system strategies for preventing micronutrient malnutrition. Food Policy. (2013) 42:11528. doi: 10.1016/j.foodpol.2013.06.008

77. McClements D. Future foods: Is it possible to design a healthier and more sustainable food supply? Nutr Bull. (2020) 45:341-54. doi: 10.1111/nbu.12457

78. Bingley C. The technological challenges of reformulating with different dietary fibres. Nutr Bull. (2020) 45:328-31. doi: 10.1111/nbu.12451

79. Abrahamse W. How to effectively encourage sustainable food choices: a mini-review of available evidence. Front Psychol. (2020) 11:1-9. doi: 10.3389/fpsyg.2020.589674

80. Abdollahi Z, Elmadfa I, Djazayery A, Golalipour M, Sadighi J, Salehi F, et al. Efficacy of flour fortification with folic acid in women of childbearing age in Iran. Ann Nutr Metab. (2011) 58:188-96. doi: 10.1159/000329726

81. Azizi F, Mehran L. Experiences in the prevention, control and elimination of iodine deficiency disorders: a regional perspective. East Mediterr Health J. (2004) 10:761-70. doi: 10.26719/2004.10.6.761

82. Ejtahed H-S, Shab-Bidar S, Hosseinpanah F, Mirmiran P, Azizi F. Estimation of vitamin $\mathrm{D}$ intake based on a scenario for fortification of dairy products with vitamin $\mathrm{D}$ in a Tehranian population, Iran. J Am Coll Nutr. (2016) 35:383-91. doi: 10.1080/07315724.2015.1022269

83. Bruins MJ, Létinois U. Adequate vitamin D Intake cannot be achieved within carbon emission limits unless food is fortified: a simulation study. Nutrients. (2021) 13:592. doi: 10.3390/nu13020592

Conflict of Interest: The authors declare that the research was conducted in the absence of any commercial or financial relationships that could be construed as a potential conflict of interest.

Publisher's Note: All claims expressed in this article are solely those of the authors and do not necessarily represent those of their affiliated organizations, or those of the publisher, the editors and the reviewers. Any product that may be evaluated in this article, or claim that may be made by its manufacturer, is not guaranteed or endorsed by the publisher.

Copyright (C) 2021 Sobhani, Omidvar, Abdollahi and Al Jawaldeh. This is an openaccess article distributed under the terms of the Creative Commons Attribution License (CC BY). The use, distribution or reproduction in other forums is permitted, provided the original author(s) and the copyright owner(s) are credited and that the original publication in this journal is cited, in accordance with accepted academic practice. No use, distribution or reproduction is permitted which does not comply with these terms. 